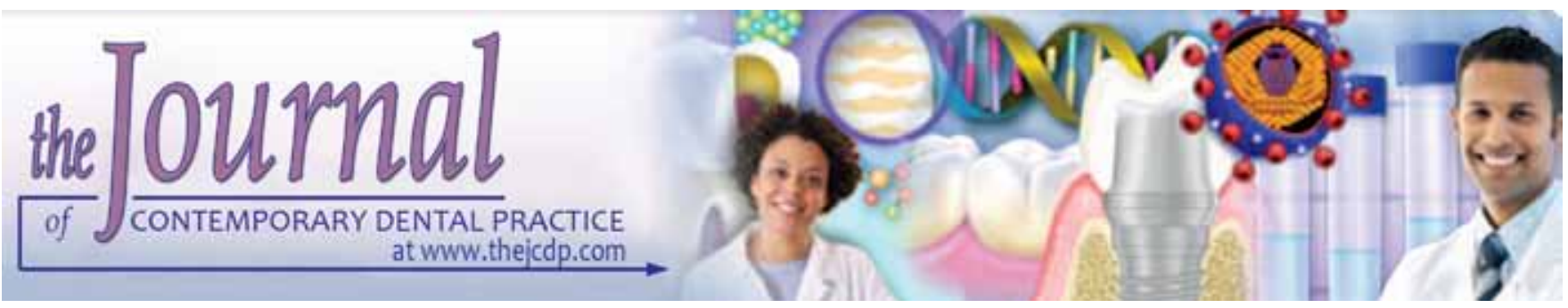

\title{
Evaluating Transportation by Comparing Several uses of Rotary Endodontic Files
}

\author{
${ }^{1}$ Ranya F Elemam, ${ }^{2} \mathrm{JA}$ Capelas, ${ }^{3}$ Mário AP Vaz, ${ }^{4}$ Nuno Viriato, ${ }^{5} \mathrm{ML}$ Pereira, ${ }^{6} \mathrm{~A}$ Azevedo, ${ }^{7} \mathrm{John}$ West
}

\begin{abstract}
Aim: To evaluate the frequent use of ProTaper Next (PTN; Dentsply Maillefer, Ballaigues, Switzerland) systems on shaping ability of root canal utilizing Solidworks (2014, Dassault Systèmes) software.

Materials and methods: Thirty-six root canals in clear resin blocks (Dentsply-Maillefer) were allocated into six experimental groups $(n=36)$. Six new sets of PTN instruments (Dentsply Maillefer, Ballaigues, Switzerland) were used six times to shape the resin blocks. A\#15 K-file was inserted to the working length (WL), followed by ProGlider (PG) to create a glide path. Sequential use of PTN instrumentation in a crown-down technique was used to reach size (30/07) apically. Macroscopic photos of the blocks were taken before and after instrumentation, layered by Paint Shop Pro 9 from JascSoftware ${ }^{\circledR}$, and then canal transportation was measured using Solidwork 2014. The data were analyzed by SPSS software version 22. Multivariate statistical analysis general linear model (GLM) was also applied. Bonferroni correction test was used in multiple comparisons and the statistical significance was set to 0.05 .
\end{abstract}

Results: There was no difference in canal transportation resulted from utilizing PTN files after six multiple uses; in addition, the PTN files showed ability to maintain the original canal anatomy, especially in the apical level, where lowest total

\footnotetext{
1,2Department of Endodontics, Faculty of Dental Medicine University of Porto, Porto, Portugal

${ }^{3}$ Department of Mechanical Engineering, Faculty of Engineering University of Porto, Porto, Portugal

${ }^{4}$ Laboratory of Optics and Experimental Mechanics, INEGIInstitute of Mechanical Engineering and Industrial Management Porto, Portugal

${ }^{5,6}$ Faculty of Dental Medicine, University of Porto, EPI UnitInstitute of Public Health University of Porto, Porto, Portugal

${ }^{7}$ Department of Endodontics, University of Washington School of Dentistry, Washington, USA
}

Corresponding Author: Ranya F Elemam, $\mathrm{PhD}$, Department of Endodontics, Faculty of Dental Medicine, University of Porto Rua Dr. Manuel Pereira da Silva 4200-393, Porto, Portugal Phone: +351 92005818, e-mail: ranya_elemam@yahoo.co.uk mean value of canal center displacement was seen ( $3 \mathrm{~mm}$ level) $(0.019 \pm 0.017)$.

Conclusion: ProTaper Next files can be used to prepare single and multiple canals in a single furcated tooth.

Clinical significance: ProTaper Next nickel-titanium (NiTi) file system is a safe instrument that respects the canal shape, allows practitioners to treat difficult cases with good results, and low risk of separation.

Keywords: Canal transportation, Multiple uses, NiTi rotary instruments, PTN, Shaping ability.

How to cite this article: Elemam RF, Capelas JA, Vaz MAP, Viriato N, Pereira ML, Azevedo A, West J. Evaluating Transportation by Comparing Several uses of Rotary Endodontic Files. J Contemp Dent Pract 2015;16(12):927-932.

Source of support: Nil

Conflict of interest: None

\section{INTRODUCTION}

Changes in materials technology have allowed newly designed endodontic files to be continuously launched in the dental market. Researchers have been extremely productive with the aim of validating the files' performances and effectiveness for clinical practice. There are many different parameters to test the performance of the rotary systems; of these characteristics, shaping or centering ability, which are both considered as two of the most important characteristics that were studied in literature. ${ }^{1,2}$ Ideal root canal preparation shape calls for continuously tapered funnels with the smallest diameter at the apical part and the widest diameter at the canal orifice. $^{3}$

Literature reports that root canal preparation techniques and/or instruments can induce canal transportation; this mechanical objective failure, in turn, can compromise the treatment outcome. Transportation may lead to inadequate elimination of infection, ${ }^{4}$ persistent radicular lesions of endodontic origin, or creation of weak canal walls leading to perforations or vertical fractures. ${ }^{5}$ 
The apical external transportation is defined as the removal of canal wall structure on the outside curve in the apical half of the canal due to the tendency of files to restore themselves to their original linear shape during canal preparation'. ${ }^{6}$ Literature indicates that nickeltitanium (NiTi) files are inclined to be more centered, are more efficient, and can achieve a more conservative canal shape than stainless steel files. ${ }^{7}$ Although the centering ability of NiTi files is due to their design and materials characteristics of shape memory and super elasticity, apical transportation can still occur. ${ }^{8}$ The search for a rotary system that creates less transportation and fully preserves the natural root canal system is still in progress. ${ }^{5}$ A few studies investigating the apical transportation in regard to ProTaper Next (PTN) instruments have been published, but none were testing the instruments' clinical viability after multiple uses. The aim of this paper is to test if the amount of root canal transportation changes upon re-using a file six times.

\section{MATERIALS AND METHODS}

A total of 36 root canals in clear resin blocks (DentsplyMaillefer Ballaigues, Switzerland) were used for this study. Each specimen had an angle of apical curvature of $60^{\circ}$ and $16 \mathrm{~mm}$ canal length (Graph 1). The blocks were given numbers from one to thirty-six, and then assembled into six groups consisting of six blocks each. The groups were organized as follows: group 1, blocks 1,7, 13, 19, 25, 31; group 2, blocks 2, 8, 14, 20, 26, 32; group 3, blocks 3, 9 , $15,21,27,33$; group 4 , blocks 4, 10, 16, 22, 28, 34; group 5, blocks 5, 11, 17, 23, 29, 35; and group 6, blocks 6, 12, 18, 24, 30, 36 (Table 1).

Six kits of PTN file systems were also given numbers from one to six; each kit used to prepare the corresponding number of the block's group. For example, files 1 for group 1, files 2 for group 2, and so forth. Each file was

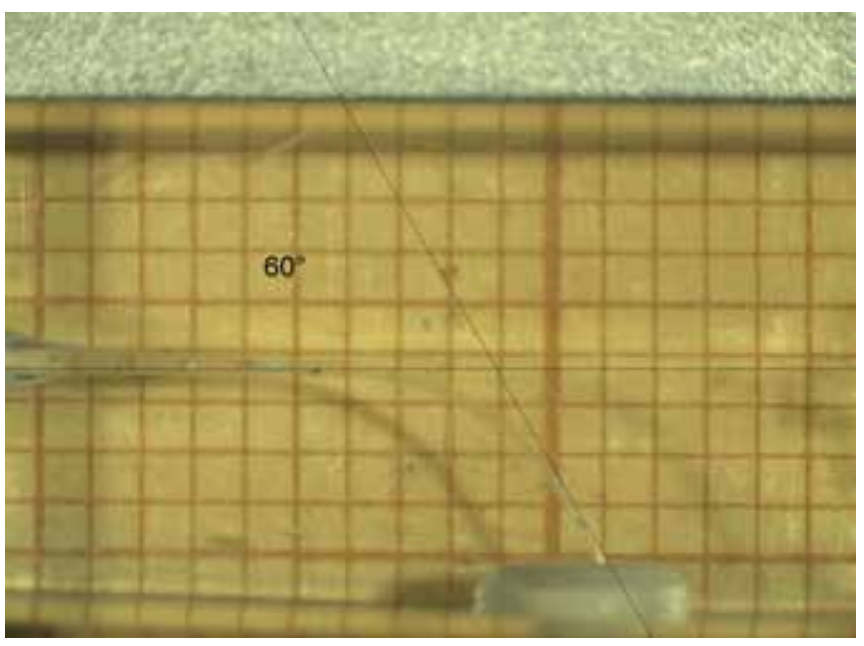

Graph 1: Resin blocks (Dentsply-Maillefer Ballaigues, Switzerland) used six times, one time in each block within each group. Blocks numbered 1, 2, 3, 4, 5, 6 were all prepared by new, first-time use files. Blocks numbered 7, 8, 9, 10, 11, 12 were prepared by files that been used once before (i.e. second-time used files). Blocks numbered 13, 14, and 15, $16,17,18$ were prepared by three-time use files, and so forth (Table 1).

\section{Root Canal Instrumentation}

Instrumentation was performed by a single operator. In all canals, working length (WL) was instrumented to the level of the apical foramen using \#10 hand K-file (Dentsply Maillefer, Ballaigues, Switzerland) and glidepath was established using ProGlider (PG) (Dentsply Maillefer, Ballaigues, Switzerland). The canals then were instrumented by PTN files using crown-down technique, driven by the WaveOne Endodontic motor (Dentsply/ Maillefer, Ballaigues, Switzerland) in rotational motion. The rotational speed was set at the recommended rotation of $350 \mathrm{rpm}$ with a torque of $2.5 \mathrm{~N} / \mathrm{cm}$. Preparation was performed using all three files in a gentle in-and-out motion until the full working length was reached. The instrumentation sequence was as follows: X1 file (size 17, 0.04 taper), followed by $\mathrm{X} 2$ file (size 26, 0.06 taper), and finally X3 (size 30, 0.07 taper). All canals were frequently irrigated with $99 \%$ ethyl alcohol using a 30-G side-vented needle and repeatedly recapitulated with K-file ISO 10 in order to keep the glide path patent.

\section{Evaluation of Canal Preparation}

In this study, all of the blocks were photographed before and after preparation using macroscopic magnifier (Leica Microsystems) with a total of $6 \times$ magnification with an image analysis program (Leica Application Suite (C) 2008 Leica Microsystems, Switzerland Ltd). All images were post-processed using Paint Shop Pro 9 from JascSoftware ${ }^{\circledR}$ (Minneapolis, MN, USA) to adjust the illumination and contrast. The functions used were Histogram Equalize and Brightness/Contrast in all images. However, in some cases it was necessary to use high-pass filtering. The preand post-instrumentation images were overlaid precisely using Adobe Photoshop Elements 10 (Adobe Systems Inc.

Table 1: Distribution of the sample blocks

\begin{tabular}{lllllll}
\hline $\begin{array}{l}\text { File } \\
\text { system } \\
\text { no. }\end{array}$ & Group & Group & Group & Group & Group & Group \\
& 1 & 2 & 3 & 4 & 5 & 6 \\
\hline F.S.1 & B1 & B7 & B13 & B19 & B25 & B31 \\
F.S.2 & B2 & B8 & B14 & B20 & B26 & B32 \\
F.S.3 & B3 & B9 & B15 & B21 & B27 & B33 \\
F.S.4 & B4 & B10 & B16 & B22 & B28 & B34 \\
F.S.5 & B5 & B11 & B17 & B23 & B29 & B35 \\
F.S.6 & B6 & B12 & B18 & B24 & B30 & B36 \\
\hline
\end{tabular}


San Jose, CA, USA). They were then transferred as one image to the SolidWorks program (SolidWorks $2014 \times 64$ Edition) and a drawing model was generated (Graph 2).

The evaluation for possible canal transportation was performed at four positions along canal wall on both proximal sides of the simulated canal (outer and inner); those locations were selected to represent the apical, middle, and coronal levels. The measurement of $1 \mathrm{~mm}$ and $3 \mathrm{~mm}$ were used to demonstrate the apical level, $5 \mathrm{~mm}$ signified the middle level, and $7 \mathrm{~mm}$ indicated the coronal level. Transportation was determined by the amount of resin removed from both the inner (concave) and the outer (convex) portions of the canal at the selected measuring points. The value was assessed by subtracting the amount of resin removed at the outer wall from that removed at the inner wall. This was done according to the formulae below:

Transportation of the canal: Deviation toward outer side of the canal-deviation toward the inner side of the canal

Transportation of the center: Outer-inner $/ 2$

Direction of transportation: Positive results means that transportation occurs mainly on the inner surface of the canal curvature and negative values indicate that transportation occurs mainly on the outer surface of the canal curvature.

\section{STATISTICAL ANALYSIS}

Statistical package for the social science (SPSS) software version 22 was used, and multivariate statistical analysis general linear model (GLM) was applied. In multiple

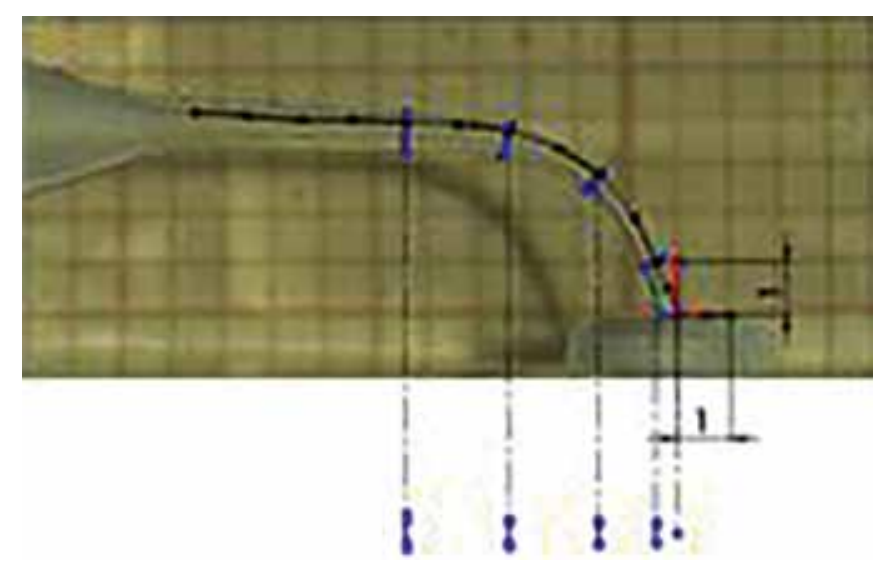

Graph 2: Model transferred onto the solidwork software (SolidWorks $2014 \times 64$ Edition) comparisons analysis, the Bonferroni correction for a global significance level of $5 \%$ was used.

\section{RESULTS}

During the root canal preparation, one file fractured. PTX1 number 6 was broken at the sixth time of attempted use while preparing block number 30 . It was consistent that, in almost all blocks, the transportation occurred more toward the outer aspect at the 1 and $3 \mathrm{~mm}$ locations; but toward the inner aspect of the canal at the 5 and $7 \mathrm{~mm}$ locations (Table 2).

Statistical analysis of mean and standard deviation value for the canal transportation was summarized in (Table 3). The lowest total mean value of canal center displacement was seen at the $3 \mathrm{~mm}$ level (0.019 \pm 0.017), whereas the highest total mean amount of canal displacement occurred at the middle $5 \mathrm{~mm}(0.055 \pm 0.022)$ followed by the $7 \mathrm{~mm}$ level $(0.036 \pm 0.026)$. This was regardless of number of file used.

It was noted that, regardless of the number of uses, the PTN files produced a similar pattern of transportation; the inclination of transportations were more predominant in 'the middle level' of $5 \mathrm{~mm}$ (Graph 3).

The rejection of covariance homogeneity after application of Mauchly's test of sphericity $(p<0.0005)$

Table 2: Directions of the mean transportation of the canal center at the four examined locations

\begin{tabular}{lllll}
\hline Blocks & $1 \mathrm{~mm}$ & $3 \mathrm{~mm}$ & $5 \mathrm{~mm}$ & $7 \mathrm{~mm}$ \\
\hline 35 Blocks & -0.030414 & -0.019657 & 0.055014 & 0.036086 \\
\hline
\end{tabular}

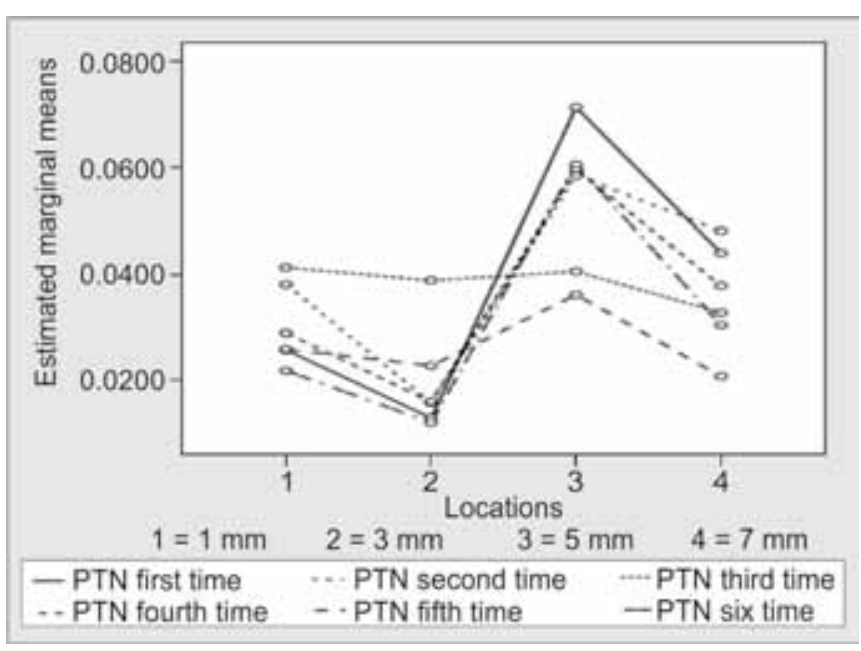

Graph 3: Means and standard deviations of transportation induced by PTN files considering location and number of use

Table 3: Measure of transportation induced by PTN files considering location and number of times of use

\begin{tabular}{llllllll}
\hline $\begin{array}{l}\text { Location } \\
m m\end{array}$ & $\begin{array}{l}\text { First time } \\
(n=6)\end{array}$ & $\begin{array}{l}\text { Second time } \\
(n=6)\end{array}$ & $\begin{array}{l}\text { Third time } \\
(n=6)\end{array}$ & $\begin{array}{l}\text { Fourth time } \\
(n=6)\end{array}$ & $\begin{array}{l}\text { Fifth time } \\
(n=5)\end{array}$ & $\begin{array}{l}\text { Sixth time } \\
(n=6)\end{array}$ & Total (35) \\
\hline 1 & $0.025 \pm 0.010$ & $0.038 \pm 0.013$ & $0.041 \pm 0.019$ & $0.028 \pm 0.014$ & $0.025 \pm 0.016$ & $0.021 \pm 0.014$ & $0.030 \pm 0.015$ \\
3 & $0.012 \pm 0.010$ & $0.015 \pm 0.015$ & $0.038 \pm 0.024$ & $0.016 \pm 0.007$ & $0.022 \pm 0.017$ & $0.012 \pm 0.011$ & $0.019 \pm 0.017$ \\
5 & $0.071 \pm 0.021$ & $0.058 \pm 0.014$ & $0.040 \pm 0.025$ & $0.059 \pm 0.018$ & $0.036 \pm 0.012$ & $0.060 \pm 0.027$ & $0.055 \pm 0.022$ \\
7 & $0.044 \pm 0.025$ & $0.048 \pm 0.030$ & $0.032 \pm 0.027$ & $0.037 \pm 0.030$ & $0.020 \pm 0.029$ & $0.030 \pm 0.016$ & $0.036 \pm 0.026$ \\
\hline
\end{tabular}


led to the consideration that the statistical GreenhouseGeisser correction should be applied. However, there were no statistically significant differences in transportation when the files' times of use were considered $(\mathrm{F}=2.138$; $\mathrm{p}=0.089$; observed power of $61.7 \%$ ) (Table 3 ). There were also no statistically significant differences in transportation when considering both location and times of use at the same time $(\mathrm{F}=1.064 ; \mathrm{p}=0.404$; observed power of $52.5 \%$ ) (Table 3 ).

\section{DISCUSSION}

The purpose of this study was to evaluate the shaping ability of the PTN filing systems after repeated usage in simulated canals under firmly controlled laboratory conditions. The reliability of acrylic resin blocks as an experimental model for the analysis of root canal preparation and endodontic preparation techniques has been previously validated. ${ }^{4,9}$ Because clinical relevancies can be transmitted as result of their outcomes, ${ }^{10}$ we are comfortable using this technique when studying endodontic procedures.

An important methodological aspect that needs to be addressed in the present study is related to the software used. Solidworks software (three-dimensional computer-aided design software) had been used in previous endodontics studies. ${ }^{11-15}$ It had been recognized that using this software is a descriptive advantage in analyzing the anatomical details of the endodontic space and in the assessment of the root canal filling. ${ }^{15}$ Without sophisticated study software, it would be difficult to reliably analyze such minute difference. Software system was used to measure transportation in two-dimensional plans for the current study.

The preservation of the root canal system's anatomy is one of the essential biologic and mechanical objectives during clinical root canal preparation. Although there are a few articles which have examined the ability of PTN to induce transportation, ${ }^{16-19}$ this is the first study assessing the effect of the repeated use of PTN on the quality of the canal preparation.

Within the study's limitation, the results have showed, that no statistically significant differences in the amount of transportation were induced by using the PTN filing systems six times (Table 3 and Graph 3). Unquestionably, this study does not endorse NiTi file reuse from patient to patient. Single patient NiTi use is the world desired standard for two important reasons, namely cross contamination and concern for fracture due to increase wear and weakness. It is important to study the instruments in non-clinical re-use situations to determine their maximum capabilities and performances. The repeating in and out pecking type shaping with the same file in six canals could clinically match the situation of treating a molar tooth with three to six canals. Given the parameters of this study, it could be concluded that the PTN instruments can enlarge the six canals with almost no transportation change with repeated use. Checking the occurrence and location of shaping errors induced by files based on frequent use is essential to achieve a successful treatment approach. This is also important when generating recommendations regarding clinical practice, especially when treating multi-rooted teeth where files will be used more than one time. Based on the result of this study, PTN appears to have the ability to maintain the original canal curvature well with minimal transportation in both single and multiple canals.

It is important to note that the instruments do maintain their cutting efficiency throughout the experiment; transportation decreases were not due to decreases in blade cutting ability. Our study showed that the files were able to maintain their cutting efficiency even after 6 times, since they could remove the resin materials on both the inner and outer sides of the tested simulated canals. The lesser amount of transportation we observed was totally related to their unique design; however a microscopic study to the topographic surface changes is requested.

Bürklein et al and Kosa et al stated that, there are various factors that effect on transportation incidence, such as alloys used in manufacturing instruments and the instruments design (cross-section, taper, size, shape and tip). ${ }^{20,21}$ In the PTN file, the cross-sectional metal mass is an off-centered rectangular shape, is machined to reduce the binding between the file and the root canal walls, ${ }^{20,22}$ and generates the enlarged space for debris removal. ${ }^{18}$ This shape could be one reason that the PTN file remains more within the canal path and slightly shifted away from the center. Generally, thermomechanically processed NiTi files cause minor canal transportation; and those made of new alloys (CM-wire, M-wire) produce almost no transportation. ${ }^{23}$ The PTN file is manufactured from M-wire alloy which is responsible for the file flexibility and cyclic fatigue resistance, while maintaining the cutting efficiency. ${ }^{24}$ This may likewise justify the current results. Use of PG in our study to create a glide path could be also another reason for the minimal amount of transportation. Elnaghy et al stated that PTN files used with PG revealed a better performance and less transportation compared to PTN files alone. ${ }^{19}$ This quality was supported by another study that suggests creating a glide path will reduce instrument deviation and lessen the amount of resulting canal transportation. ${ }^{25}$

One study measured the effect of the repeated use of ProTaper Universal rotary instruments on the shaping ability in resin simulators, and found significant differences between the numbers of files used on the canal shape. This effect was explained as a result of reduction in 
cutting efficiency of the instrument due to a modification of the cutting edge. ${ }^{26}$ This is nonparallel to our study; due to many different factors in the construction of the two instruments. For example, the instruments' tapering patterns, cross-sectional profiles, axis of rotations, and alterations in metallurgic processing are all different. The combination of these factors makes instrument comparisons difficult and inaccurate.

Most previous research papers evaluated the transportation of the canal as an entire entity while this study examined the amount of transportation of the center of the root canal. The transported volume amount was calculated by dividing the value of the difference between the widths of resin removed from the measured locations of the aspect walls by two. However, despite the difference in methodology, as well as the fact that other studies have evaluated the entire canal transportation, the findings of our study are comparable to other studies that have evaluated the same files. ${ }^{16-19}$ For example, at the apical level of $3 \mathrm{~mm}$, our result showed mean of transportation (0.019 \pm 0.017$)$ (Table 3). Elnaghy et al, found that the transportation of the entire canal at same level is $(0.05 \pm 0.02)^{19}$ while Capar et al mentioned $(0.09$ $\pm 0.08)$ at $2 \mathrm{~mm} .{ }^{17}$

Wu et al demonstrated that more than $0.3 \mathrm{~mm}$ apical transportation will negatively affect the root canal system seal. ${ }^{27}$ In the present study, all transportation values at apical positions were less than 0.3 , in $1 \mathrm{~mm}=(0.030 \pm$ $0.015)$ and in $3 \mathrm{~mm}=(0.019 \pm 0.017)$ (Table 3 and Graph 3$)$. The direction of the transportation of PTN rotary NiTi instruments detected in this study was, in general, toward the outer aspect of the curve at the apex of the preparation, and toward the inner aspect of the canal curve at middle parts (Table 2). There are many studies that confirm this tendency of rotary endodontic instruments. ${ }^{4}$

The reason is explained by the construction of the files. When the files are used to shape curved canals, the restoring forces of the metal in the files tend to return them to their original shape and when the files straighten toward the outer side of the curvature, they apply more pressure, removing more material, and cut more in this area. This same effect decreases their cutting more coronally along the inner wall. ${ }^{28}$

Despite the great advantages of rotary NiTi files vs stainless steel, they may undergo fracture as a result of torsional or flexural fatigue. ${ }^{29}$ In the present study, only one NiTi rotary file was separated; this did not occur until the sixth use. This quite possibly occurred due to the resistance of the resin block material. This resistance may have resulted in an 'unwinding' of the instrument flutes, consequently producing a stress point and fracture of the files. ${ }^{30,31}$ Fracture leads to the assumption that breakage of a repeatedly used file may be avoided when the file is handled carefully, the pressure on the file reduced and by creation of a glide path during preparation. Accordingly, the torsional failure reduced, as well as the chance of file separation. ${ }^{32}$

\section{CONCLUSION}

Under the conditions of this study, PTN files (Dentsply Maillefer, Ballaigues, Switzerland) respect the original canal curvature well and were safe to use repeatedly with few incidences of transportation.

Clinical significance: ProTaper Next can be safely used in different canals $6 \times$ with little or no canal transportation while maintaining their cutting ability. It maintains the canal shape and showed little risk of separation.

\section{REFERENCES}

1. Gundappa M, Bansal R, Khoriya S, Mohan R. Root canal centering ability of rotary cutting nickel-titanium instruments: a meta-analysis. J Conserv Dent 2014;17(6):504-509.

2. Versümer J, Hülsmann M, Schäfers F. A comparative study of root canal preparation using ProFile, 04 and Lightspeed rotary NiTi instruments. Int Endod J 2002;35(1):37-46.

3. Schilder H. Cleaning and shaping the root canal. Dent Clin North Am 1974;18(2):269-296.

4. Weine F, Kelly R, Lio P. The effect of preparation procedures on original canal shape and on apical foramen shape. J Endod 1975;1:262-266.

5. Peters OA. Current challenges and concepts in the preparation of root canal systems: a review. J Endod 2004;30(8):559-567.

6. American Association of Endodontists Glossary of Endodontic Terms. 7th ed. Chicago: AAE; 2003.

7. Kum K-Y, Spängberg L, Cha BY, Il-Young J, Seung-Jong L, Chan-Young L. Shaping ability of three ProFile rotary instrumentation techniques in simulated resin root canals. J Endod 2000;26(12):719-723.

8. Giannastasio D, Rosa RAd, Peres BU, Barreto MS, Dotto GN, Kuga MC, et al. Wizard CD Plus and ProTaper Universal: analysis of apical transportation using new software. J Applied Oral Sci 2013;21(5):468-474.

9. Ponti TM, McDonald N, Kuttler S, Strassler HE, Dumsha TC. Canal-centering ability of two rotary file systems. J Endod 2002;28(4):283-286.

10. Ahmad M. The validity of using simulated root canals as models for ultrasonic instrumentation. J Endod 1989; 15(11):544-547.

11. Montalvão D, Alçada FS. Numeric comparison of the static mechanical behavior between profile GT and profile GT series X rotary nickel-titanium files. J Endod 2011;37(8): 1158-1161.

12. Zhang E-W, Cheung GSP, Zheng Y-F. Influence of crosssectional design and dimension on mechanical behavior of nickel-titanium instruments under torsion and bending: a numerical analysis. J Endod 2010;36(8):1394-1398.

13. de Arruda Santos L, López JB, de Las Casas EB, de Azevedo Bahia MG, Buono VTL. Mechanical behavior of three nickeltitanium rotary files: a comparison of numerical simulation 
with bending and torsion tests. Materials Science and Engineering: C 2014;37(1):258-263.

14. El Din Mohamed Saber S, Seeda AA, Mohammad M, Hassanien E. The effect of instrument material, taper and degree of root canal curvature on cyclic fatigue of rotary nickel-titanium instruments. Endodontic Practice Today 2013;7(1):59-64.

15. Stratul S, Didilescu A, Grigorie M, Ianes E, Rusu D, Nica L. How accurate replicates the Thermafil System the morphology of the apical endodontic space? An ex vivo study. Rom J Morphol Embryol 2011;52(1):145-151.

16. Bürklein S, Mathey D, Schäfer E. Shaping ability of ProTaper Next and BT-RaCe nickel-titanium instruments in severely curved root canals. Int Endod J 2015;48(8):774-781.

17. Capar ID, Ertas H, Ok E, Arslan H, Ertas ET. Comparative study of different novel nickel-titanium rotary systems for root canal preparation in severely curved root canals. J Endod 2014;40(6):852-856.

18. Saber SEDM, Nagy MM, Schäfer E. Comparative evaluation of the shaping ability of ProTaper Next, iRaCe and Hyflex CM rotary NiTi files in severely curved root canals. Int Endod J 2015;48(2):131-136.

19. Elnaghy AM, Elsaka SE. Evaluation of root canal transportation, centering ratio, and remaining dentin thickness associated with ProTaper Next instruments with and without glide path. J Endod 2014;40(12):2053-2056.

20. Bürklein S, Schäfer E. Critical evaluation of root canal transportation by instrumentation. Endod Topics 2013; 29(1):110-124.

21. Kosa DA, Marshall G, Baumgartner JC. An analysis of canal centering using mechanical instrumentation techniques. J Endod 1999;25(6):441-445.

22. Hashem AA, Ghoneim AG, Lutfy RA, Foda MY, Omar GA. Geometric analysis of root canals prepared by four rotary NiTi shaping systems. J Endod 2012;38(7):996-1000.
23. Kocak MM, Cicek E, Kocak S, Saglam BC, Yilmaz N. Apical extrusion of debris using ProTaper Universal and ProTaper Next rotary systems. Int Endod J 2015;48(3):283-286.

24. Zhao D, Shen Y, Peng B, Haapasalo M. Micro-computed tomography evaluation of the preparation of mesiobuccal root canals in maxillary first molars with Hyflex CM, Twisted Files, and K3 instruments. J Endod 2013;39(3): 385-388.

25. Berutti E, Chiandussi G, Paolino DS, Scotti N, Cantatore G, Castellucci A, et al. Canal shaping with WaveOne Primary reciprocating files and ProTaper system: a comparative study. J Endod 2012;38(4):505-509.

26. Ounsi HF, Franciosi G, Paragliola R, Goracci C, Grandini S. Effect of repeated use on the shaping ability of ProTaper Universal rotary files. Int Dent SA 2010;12:30-35.

27. Wu MK, Fan B, Wesselink PR. Leakage along apical root fillings in curved root canals. Part I: effects of apical transportation on seal of root fillings. J Endod 2000;26(4):210-216.

28. Ayar L, Love R. Shaping ability of ProFile and K3 rotary NiTi instruments when used in a variable tip sequence in simulated curved root canals. Int Endod J 2004;37(9):593-601.

29. Arens FC, Hoen MM, Steiman HR, Dietz GC. Evaluation of single-use rotary nickel-titanium instruments. J Endod 2003;29(10):664-666.

30. Iqbal MK, Kohli MR, Kim JS. A retrospective clinical study of incidence of root canal instrument separation in an endodontics graduate program: a PennEndo database study. J Endod 2006;32(11):1048-1052.

31. Schafer E, Florek H. Efficiency of rotary nickel-titanium K3 instruments compared with stainless steel hand K-FlexofilePart 1: shaping ability in simulated curved canals. Int Endod J 2003;36(3):199-207.

32. Kitchens GG, Liewehr FR, Moon PC. The effect of operational speed on the fracture of nickel-titanium rotary instruments. J Endod 2007;33(1):52-54. 